\section{Review: Quality of life in lower limb peripheral vascular surgery}

Reprints and sepub.co.uk/journalsPermissions.nav DOI: $10.1177 / 1708538$ | I557896। vas.sagepub.com

\author{
JMW Donker', J de Vries², GH Ho', F Bastos Gonçalves ${ }^{3,4}$, \\ SE Hoeks ${ }^{5}$, HJM Verhagen ${ }^{3}$ and L van der Laan'
}

SAGE

\begin{abstract}
Purpose: Vascular intervention studies generally consider patency and limb salvage as primary outcomes. However, quality of life is increasingly considered an important patient-oriented outcome measurement of vascular interventions. Existing literature was analyzed to determine the effect of different treatments on quality of life for patients suffering from either claudication or critical limb ischemia.

Basic methods: A review of the literature was undertaken in the Medline library. A search was performed on quality of life in peripheral arterial disease. Results were stratified according to treatment groups.

Principal findings: Twenty-one articles described quality of life in approximately 4600 patients suffering from peripheral arterial disease. Invasive treatment generally results in better quality of life scores (at a maximum of 2 years of follow-up), compared with non-invasive treatment. In patients with critical limb ischemia, successful revascularization improves quality of life scores. Only one study reported long-term results.

Conclusions: Increase in quality of life scores can be found for any intervention performed for peripheral arterial disease. However, there is scarce information on long-term quality of life after vascular intervention.
\end{abstract}

\title{
Keywords
}

Quality of life, vascular, peripheral bypass surgery, peripheral arterial disease, peripheral vascular disease

\section{Introduction}

Peripheral arterial disease (PAD) is commonly caused by atherosclerosis of peripheral arteries. The prevalence of PAD is $3-10 \%$ in the current population and ranges up to $15-20 \%$ in the elderly population. ${ }^{1-4}$ PAD is categorized by the Rutherford classification. ${ }^{5}$ Rutherford classifications 1 to 3 are used for patients suffering from intermittent claudication. These patients can be treated either with exercise therapy or revascularization. ${ }^{1}$

In patients with critical limb ischemia, Rutherford classifications 4 to 6 , the need for intervention is inevitable, which can either be performed by a percutaneous transluminal angioplasty (PTA), peripheral bypass surgery or, when this is technically not possible, primary amputation or palliation. ${ }^{1}$ Typically, reported outcomes of vascular interventions include walking distance, patency rates, limb salvage rates and operative mortality. ${ }^{5}$ However, these outcomes may reflect a physician-oriented view on results.

Quality of life (QoL) is increasingly considered an important outcome of vascular interventions. ${ }^{2,6}$ It is an individual assessment of physical, psychological and social well-being that is based on the definition of health by the World Health Organization. ${ }^{7}$ QoL incorporates a patient's individual perception of his/ her disease and functioning. ${ }^{8}$ Patients suffering from PAD frequently cope with a deprived health status and QoL due to the general effects of the disease and co-morbid conditions. ${ }^{8}$ In this perspective, QoL is a patient-oriented way of evaluating results and may

\footnotetext{
'Department of Surgery, Amphia Hospital, Breda, The Netherlands ${ }^{2}$ Department of Medical Psychology, Tilburg University \& St. Elisabeth Hospital, Tilburg, The Netherlands

${ }^{3}$ Department of Vascular Surgery, Erasmus University Medical Center, Rotterdam, The Netherlands

${ }^{4}$ Department of Angiology and Vascular Surgery, Hospital de Santa Marta, Lisbon, Portugal

${ }^{5}$ Department of Epidemiology, Erasmus University Medical Center, Rotterdam, The Netherlands
}

\section{Corresponding author:}

L van der Laan, Department of Surgery, Amphia Hospital, P.O. Box 90158 , 4800 RK Breda, The Netherlands.

Email: Ivanderlaan@amphia.nl 
provide a better-balanced estimate of the impact of a certain intervention for patients.

There are reviews available on different topics of QoL in vascular surgery. However, these are mostly outdated and they assess only a small spectrum of QoL in vascular surgery.

We decided to conduct a systematic literature review to analyze the effect of exercise therapy, endovascular procedures and surgical interventions on the QoL of patients suffering from lower limb ischemia.

\section{Methods}

This review is based on a search in the Medline library, which was accessed by the PubMed search engine on 31 December 2011. The search was based on both medical subject headings $[\mathrm{MeSH}]$ and normal search terms and was performed by the first author, aided by the institution's librarian.

Terms used were "Peripheral Vascular Diseases" $[\mathrm{MeSH}]$ and "quality of life" [MeSH] (215 results) and "Peripheral arterial disease" $[\mathrm{MeSH}]$ and "Quality of Life" (36 results). All titles and abstracts were read, and all articles which were not referring to QoL in peripheral vascular surgery were excluded $(n=232)$. Nineteen manuscripts were selected for thorough revision. Three manuscripts were excluded, and from all references read five manuscripts were included in the review. QoL was defined as outcome, either primary or secondary. All relevant articles were fully read, and possible references were included and read as well.

\section{Inclusion criteria}

All papers that reported QoL scores after the following interventions in PAD were included: exercise therapy, PTA procedures and surgical revascularization. QoL had to be assessed with a questionnaire. Only articles published in English were included. Papers had to be published before 1 January 2012.

\section{QoL assessment}

There are many different questionnaires used to assess patients' QoL. There are generic QoL questionnaires like the WHOQOL and the EQ-5D questionnaires, disease specific questionnaires like the VascuQoL questionnaire or health status questionnaires like the SF-36 and RAND-36 questionnaires.

\section{Results}

A total of 21 studies were included which analyzed approximately 4600 patients. These studies were distributed by type of intervention as follows: QoL after exercise therapy $(N=5)$; QoL after endovascular procedures $(N=11)$; and QoL after open surgery $(N=13)$.

Many studies have analyzed and reported QoL results after all different types of vascular treatment, in either patients suffering from intermittent claudication ${ }^{9-16}$ or patients with critical limb ischemia, ${ }^{17-21}$ or studies with both groups of patients. ${ }^{22-32}$ There are studies comparing endovascular treatment with bypass surgery, $9,12,18,19,24,28$ studies comparing endovascular therapy with exercise therapy, ${ }^{9,14}$ studies comparing autologous bypass surgery with Polytetrafluoroethylene (PTFE) bypass surgery ${ }^{22}$ and studies analyzing QoL after a single intervention. ${ }^{13,15-17,20,21,23,25,27,29-32}$

\section{QoL after exercise therapy}

Five articles assessed QoL in patients after exercise therapy. ${ }^{9,13-16}$ All articles assessed QoL in patients suffering from intermittent claudication. Exercise therapy, both supervised and unsupervised, resulted in increment in QoL at a maximum of 24 months of follow-up. However, results of supervised exercise therapy were better compared to the unsupervised exercise therapy. ${ }^{13}$ Patients receiving invasive treatment (both endovascular and surgical reconstruction) showed more increment in QoL than patients who only received exercise therapy. ${ }^{14}$ For detailed information on studies analyzing QoL after exercise therapy, see Table 1.

\section{QoL after endovascular procedures}

Eleven articles assessed QoL in patients after endovascular procedures. 9,12,14,18,19,23-25,28,31,32 For patients suffering from intermittent claudication, an increase in QoL could be expected up to 2 years of follow-up. ${ }^{14}$

Patients with critical limb ischemia also showed increased QoL up to 36 months of follow-up after endovascular treatment. $^{18}$ The difference in QoL between patients suffering from critical limb ischemia and patients suffering from intermittent claudication remains unclear, as different papers report in contrast to each other. ${ }^{24,25}$ A study analyzing QoL in critical limb ischemia patients after endovascular procedures, bypass surgery and secondary amputations stated that achieving limb salvage was related to better QoL. ${ }^{19}$ One case-control study reported that both intermittent claudication patients and critical limb ischemia patients cope with a deprived QoL score compared to matched healthy control subjects. ${ }^{28}$

Endovascular treatment can increase QoL, even for chronically occluded superficial femoral arteries. ${ }^{23}$ For detailed information on studies analyzing QoL after PTA, see Table 2. 


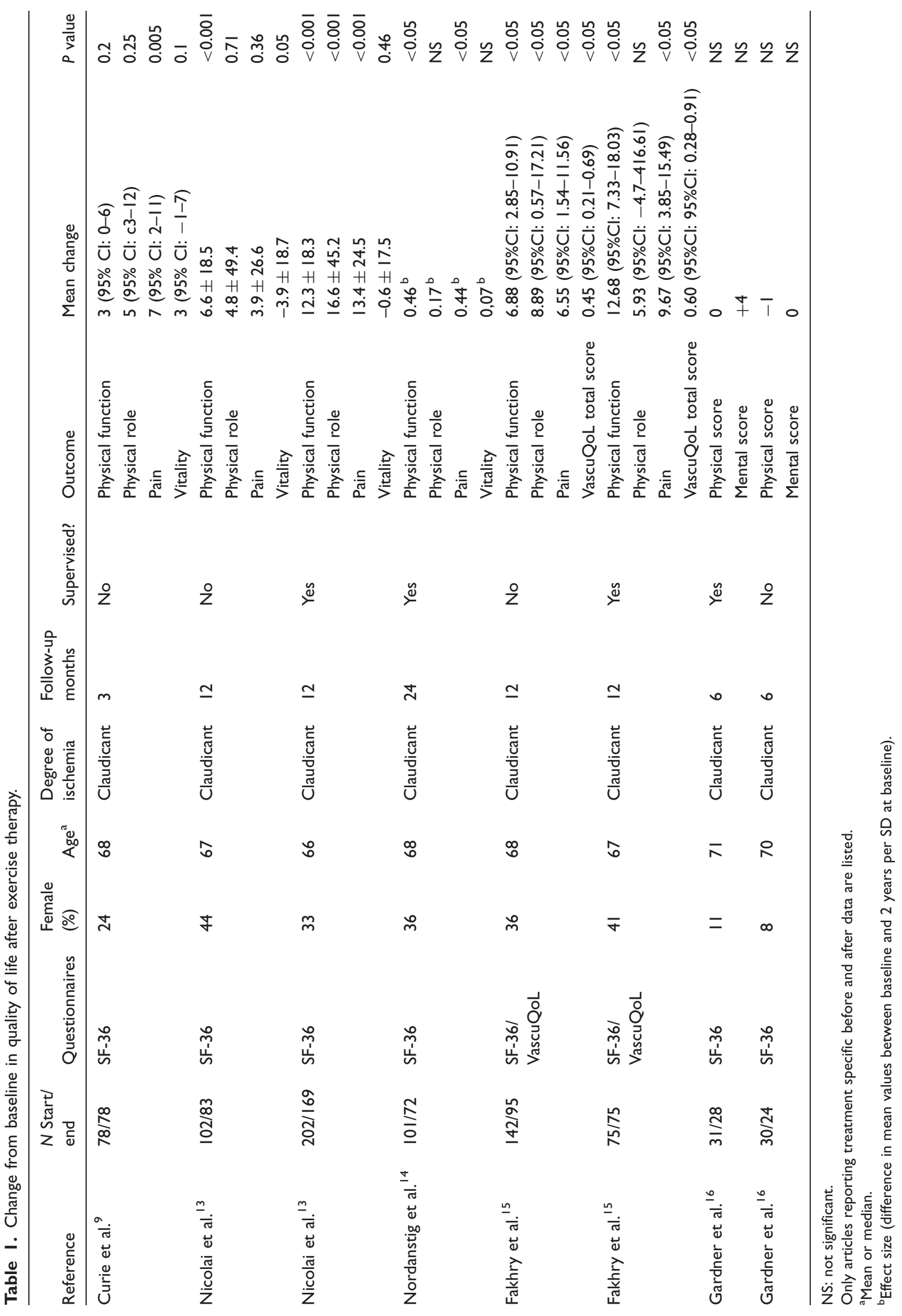




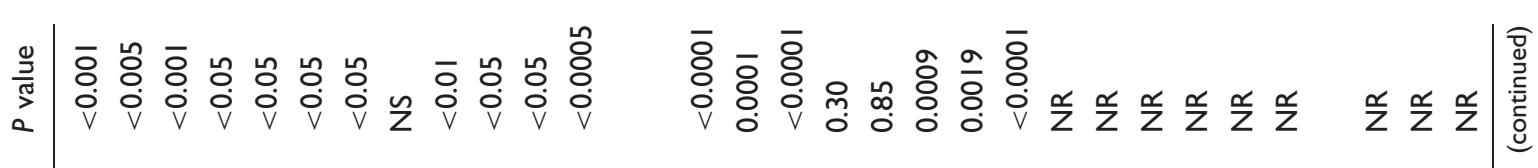

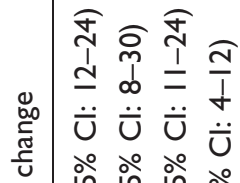

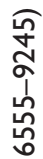

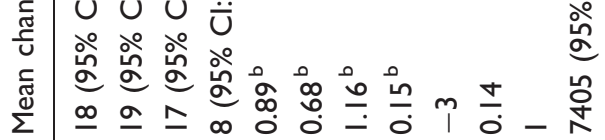

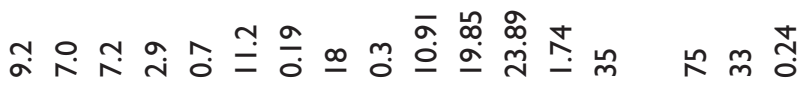

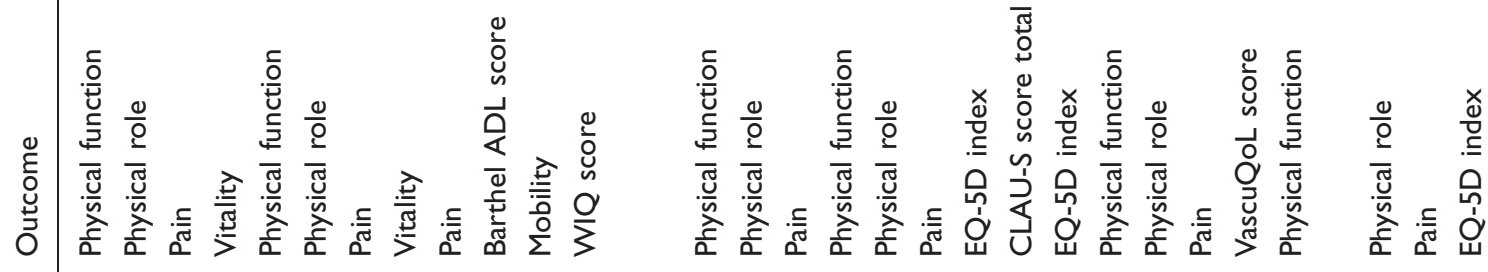

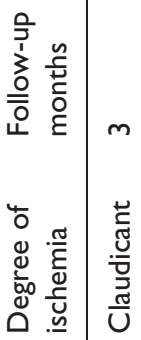

$\stackrel{\pi}{\stackrel{\infty}{\infty}}$

$\infty$

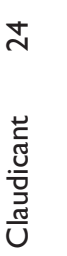

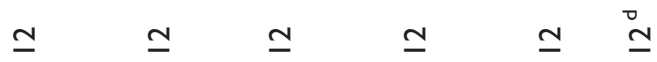

$\stackrel{4}{ }$

离 ฮ

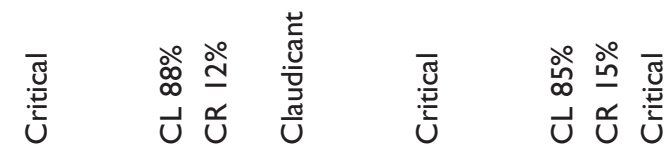

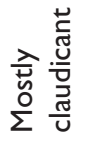

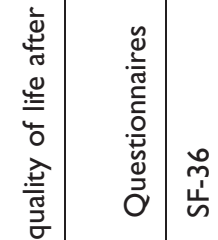

$\stackrel{\infty}{m}$

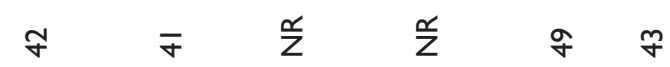

๙ิ

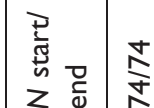

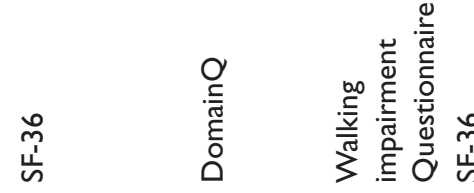

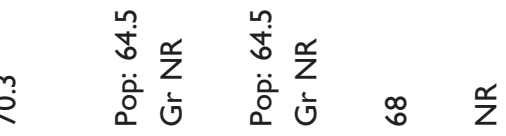

เิ

$\begin{array}{lll}\frac{0}{1} & \stackrel{0}{8}\end{array}$

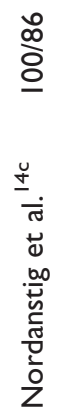

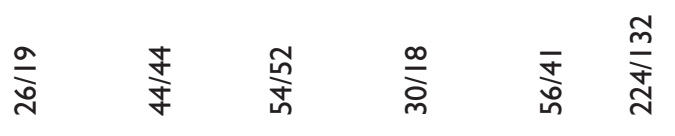

$\frac{\mathfrak{m}}{\stackrel{p}{\underline{q}}}$

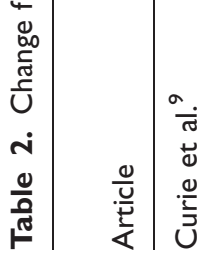

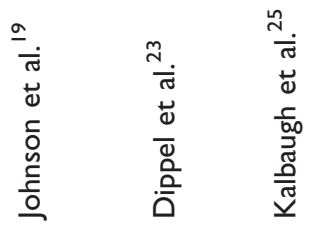

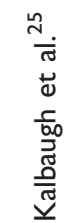

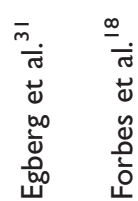

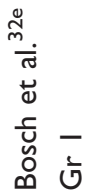




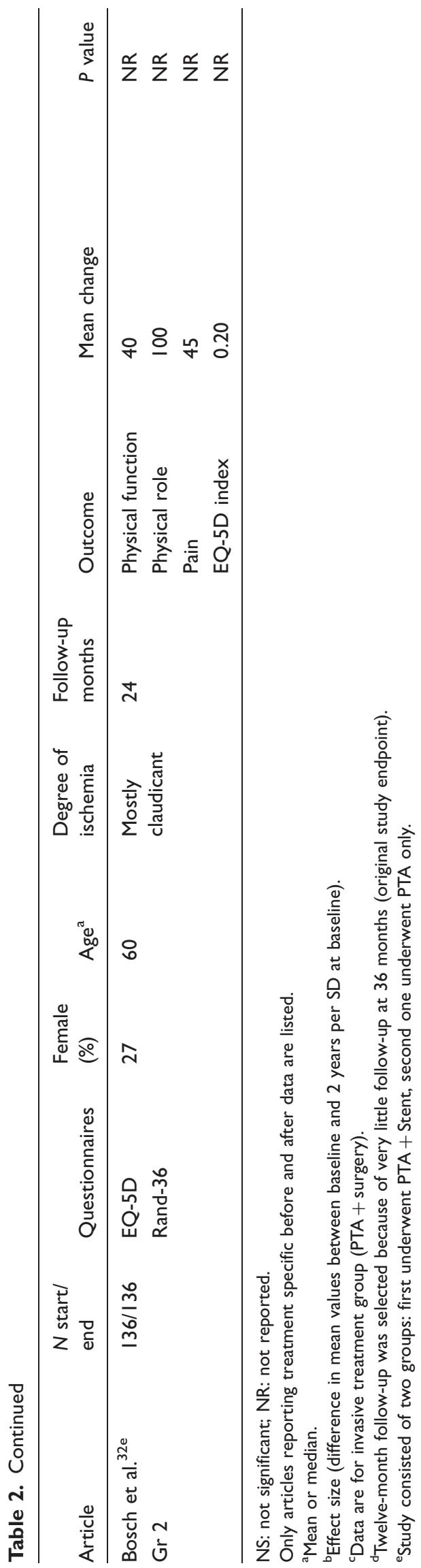

\section{QoL after open surgical procedures}

Thirteen articles assessed QoL in patients after surgical revascularization procedures. ${ }^{9,12,14,17-20,22,24,27-30}$ Surgical revascularization improved QoL in patients suffering from both intermittent claudication and critical limb ischemia, at least for two to three years after surgery. The increment in QoL achieved by a surgical revascularization intervention was significantly better compared to walking exercise. ${ }^{9,14}$

Little is known about the long-term effect of endovascular or surgical reconstructive interventions on patients' QoL. Only one prospective study analyzed results after more than 2 years of follow-up, after both endovascular and surgical reconstructive procedures. ${ }^{18}$ They showed an increment in QoL for both procedures after 3 years of follow-up. A case-control study $^{28}$ showed that QoL scores of patients after both endovascular and surgical reconstructions (mean 3.5 years for surgery, 2.7 years for PTA) were lower compared to healthy subjects. One study analyzed long-term follow-up results (mean follow-up of 11 years) after reconstructive surgery, ${ }^{29}$ and they reported decrement in QoL scores for patients treated with surgical reconstructions. Especially patients who experienced an adverse event during the follow-up period scored lower on QoL. For detailed information on studies analyzing QoL after surgical revascularization, see Table 3.

\section{Discussion}

Our systematic review involving approximately 4600 patients subjected to supervised walking therapy, endovascular or open revascularization revealed that for every performed intervention in PAD, some degree of increase in QoL scores was observed. However, this improvement varies significantly depending on the type of population (intermittent claudication vs. critical limb ischemia), the intervention performed and the type of QoL scoring method used. QoL scores also varied significantly with the duration of follow-up, which suggests that QoL in patients with PAD is very dynamic and multifactorial.

For patients suffering from intermittent claudication, walking advice itself can increase QoL scores as demonstrated by Nicolai et al. ${ }^{13}$ However, supervised walking exercise results in better QoL scores. Nordanstig et al. ${ }^{14}$ and Currie et al. ${ }^{9}$ reported increased QoL scores after walking exercise. They also stated that QoL could be further improved after invasive treatment with either endovascular intervention or surgical treatment.

In patients suffering from critical limb ischemia, endovascular treatment can result in improved QoL scores. A few studies analyzed the difference in QoL between endovascular and surgical intervention. 


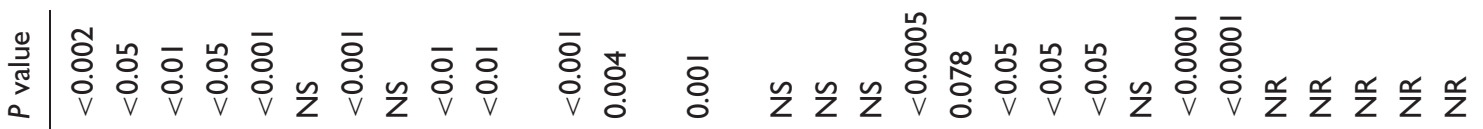

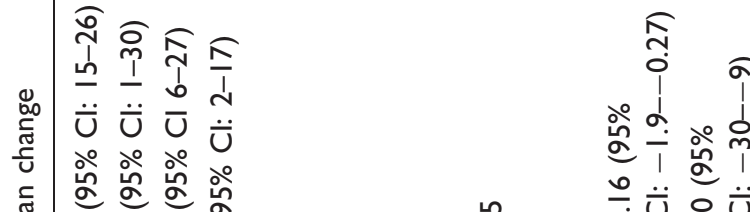

焉

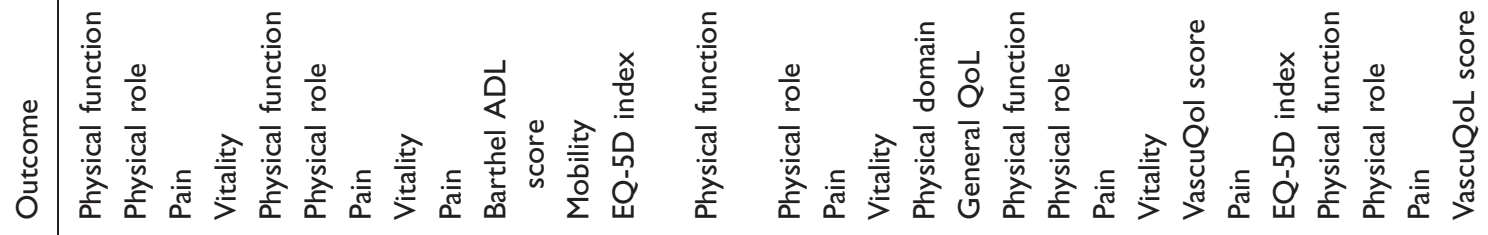

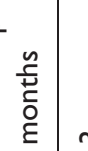

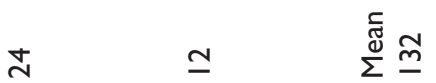

$m \quad \underline{\infty}$

$\simeq \stackrel{0}{\simeq}$

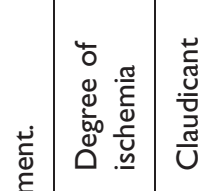

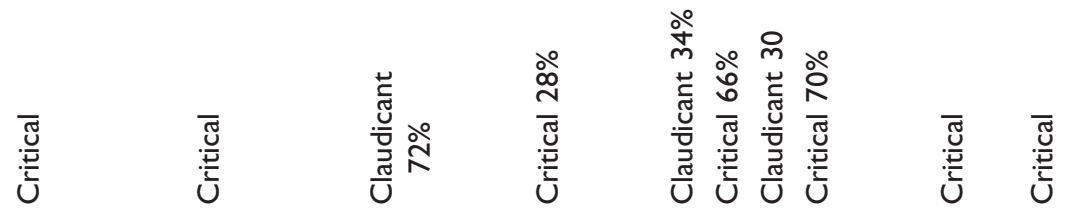

$\stackrel{8}{\stackrel{8}{8}}$

$\pi \quad \kappa$

ลิ กิ

o 은

这 $\overparen{\frac{0}{\pi}}$

$\stackrel{\infty}{\sim}$ ร

ลิ

ำ 믄

m $\stackrel{\infty}{m}$

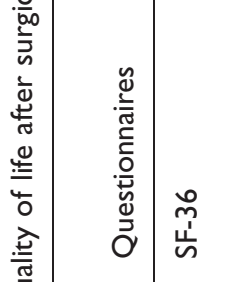

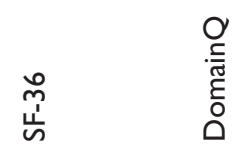

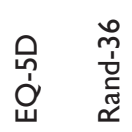

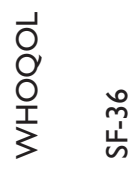

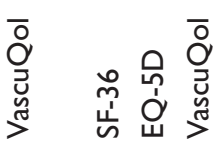

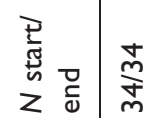

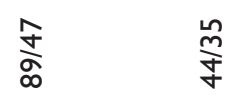

$\underset{\substack{n \\ \stackrel{n}{\sim}}}{\stackrel{n}{a}}$

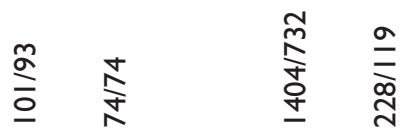

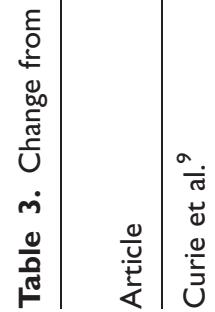

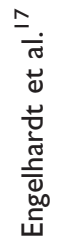

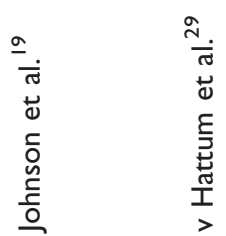

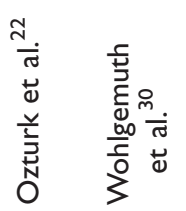

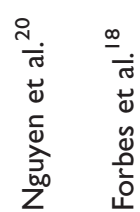


They all showed increased QoL scores, but a significant difference between both treatments was not found. This suggests that the decision for treatment modality should not be based on QoL, which is similar after both types of intervention.

Surgical reconstructive intervention will increase patients' QoL scores, at least for short-term analyses. The long-term analysis reported by van Hattum et al. ${ }^{29}$ showed that the increment in QoL scores may not be everlasting, and QoL scores may deteriorate at longterm follow-up.

Very little is known on QoL after major lower limb amputation. Only two studies were found which assessed QoL after this type of intervention. Johnson et al. ${ }^{19}$ stated that QoL of patients suffering from critical limb ischemia is higher in patients who underwent successful revascularization compared to patients who underwent primary or secondary amputations.

Remes et al. ${ }^{33}$ stated that PAD patients who received lower extremity amputation have lower QoL scores compared to healthy control subjects. How PAD patients' QoL relates to other chronically illnesses is unclear. This study only analyzed QoL after amputation and compared these scores to a healthy control subject, not evaluating QoL change over time.

There are several problems we encountered while working on our study. First, in this review we used the term QoL even for studies that used health status questionnaires because they presented their results as QoL scores. For instance, the SF-36 (and the Rand-36) is a health status questionnaire. A study performed by Breek et al., ${ }^{8}$ showed that there is a discrepancy between QoL scores and health status scores. Patients who scored relatively high on one scale could easily score lower on the other. Therefore, it is hard to compare studies with different questionnaires in a reliable way. Health status questionnaires should generally not be used for assessing patients' QoL. Best results can be achieved by using either a general QoL questionnaire or a disease specific QoL questionnaire. Also, the duration of follow-up in the included studies varied significantly, which makes it difficult to compare the results. Moreover, the number of included patients in many studies is small, which may lead to type-II errors. Finally, no studies were randomized and most were retrospective observational studies. There may be significant publication bias in the included studies, as positive results are more likely to be reported and published.

In conclusion, all types of interventions performed in patients with PAD may improve QoL or QoL-related aspects. However, the increment is not homogeneous and depends on the studied population, type of intervention, questionnaire used, scoring method and duration of follow-up. Little is known about the long-term follow-up QoL after vascular intervention. Only a small number of studies analyzed QoL in patients who underwent lower limb amputation. These studies were not specifically designed to analyze the effect of lower limb amputation on QoL scores before and after surgery. Randomized studies are required to provide evidence of the true benefit of intervention in patients with PAD.

\section{Declaration of conflicting interests}

The author(s) declared no potential conflicts of interest with respect to the research, authorship, and/or publication of this article.

\section{Funding}

The author(s) received no financial support for the research, authorship, and/or publication of this article.

\section{References}

1. Hirsch AT, Haskal ZJ, Hertzer NR, et al. ACC/AHA 2005 practice guidelines for the management of patients with peripheral arterial disease (lower extremity, renal, mesenteric, and abdominal aortic): a collaborative report from the American Association for Vascular Surgery/Society for Vascular Surgery, Society for Cardiovascular Angiography and Interventions, Society for Vascular Medicine and Biology, Society of Interventional Radiology, and the ACC/AHA Task Force on Practice Guidelines (Writing Committee to Develop Guidelines for the Management of Patients With Peripheral Arterial Disease): endorsed by the American Association of Cardiovascular and Pulmonary Rehabilitation; National Heart, Lung, and Blood Institute; Society for Vascular Nursing; TransAtlantic Inter-Society Consensus; and Vascular Disease Foundation. Circulation 2006; 113: e463-e654.

2. Rooke TW, Hirsch AT, Misra S, et al. ACCF/AHA focused update of the guideline for the management of patients with peripheral artery disease (updating the 2005 guideline): a report of the American College of Cardiology Foundation/American Heart Association Task Force on practice guidelines. Circulation 2011; 124: 2020-2045.

3. Selvin E and Erlinger TP. Prevalence of and risk factors for peripheral arterial disease in the United States: results from the National Health and Nutrition Examination Survey, 1999-2000. Circulation 2004; 110: 738-743.

4. Norgren L, Hiatt WR, Dormandy JA, et al. Inter-society consensus for the management of peripheral arterial disease (TASC II). Eur J Vasc Endovasc Surg 2007; 33 (Suppl 1): S1-S75.

5. Rutherford RB, Baker JD, Ernst C, et al. Recommended standards for reports dealing with lower extremity ischemia: revised version. J Vasc Surg 1997; 26: 517-538.

6. Czajkowski SM. Health-related quality of life outcomes in clinical research: NHLBI policy and perspectives. Ann Thorac Surg 1998; 66: 1486-1487. 
7. Saxena S and Orley J. Quality of life assessment: the world health organization perspective. Eur Psychiatry 1997; 12S3: 263s-266s.

8. Breek JC, de Vries J, van Heck GL, et al. Assessment of disease impact in patients with intermittent claudication: discrepancy between health status and quality of life. J Vasc Surg 2005; 41: 443-450.

9. Currie IC, Wilson YG, Baird RN, et al. Treatment of intermittent claudication: the impact on quality of life. Eur J Vasc Endovasc Surg 1995; 10: 356-361.

10. Khaira HS, Hanger R and Shearman CP. Quality of life in patients with intermittent claudication. Eur J Vasc Endovasc Surg 1996; 11: 65-69.

11. Breek JC, Hamming JF, De Vries J, et al. The impact of walking impairment, cardiovascular risk factors, and comorbidity on quality of life in patients with intermittent claudication. J Vasc Surg 2002; 36: 94-99.

12. Letterstal A, Forsberg C, Olofsson P, et al. Risk attitudes to treatment among patients with severe intermittent claudication. J Vasc Surg 2008; 47: 988-994.

13. Nicolai SP, Teijink JA and Prins MH. Multicenter randomized clinical trial of supervised exercise therapy with or without feedback versus walking advice for intermittent claudication. J Vasc Surg 2010; 52: 348-355.

14. Nordanstig J, Gelin J, Hensater M, et al. Walking performance and health-related quality of life after surgical or endovascular invasive versus non-invasive treatment for intermittent claudication - a prospective randomised trial. Eur J Vasc Endovasc Surg 2011; 42: 220-227.

15. Fakhry F, Spronk S, de Ridder M, et al. Long-term effects of structured home-based exercise program on functional capacity and quality of life in patients with intermittent claudication. Arch Phys Med Rehabil 2011; 92: 1066-1073.

16. Gardner AW, Katzel LI, Sorkin JD, et al. Exercise rehabilitation improves functional outcomes and peripheral circulation in patients with intermittent claudication: a randomized controlled trial. J Am Geriatr Soc 2001; 49: 755-762.

17. Engelhardt M, Bruijnen H, Scharmer C, et al. Prospective 2-years follow-up quality of life study after infrageniculate bypass surgery for limb salvage: lasting improvements only in non-diabetic patients. Eur $J$ Vasc Endovasc Surg 2008; 36: 63-70.

18. Forbes JF, Adam DJ, Bell J, et al. Bypass versus Angioplasty in Severe Ischaemia of the Leg (BASIL) trial: health-related quality of life outcomes, resource utilization, and cost-effectiveness analysis. J Vasc Surg 2010; 51(5 Suppl): 43S-51S.

19. Johnson BF, Singh S, Evans L, et al. A prospective study of the effect of limb-threatening ischaemia and its surgical treatment on the quality of life. Eur J Vasc Endovasc Surg 1997; 13: 306-314.

20. Nguyen LL, Moneta GL, Conte MS, et al. Prospective multicenter study of quality of life before and after lower extremity vein bypass in 1404 patients with critical limb ischemia. J Vasc Surg 2006; 44: 977-983; discussion 83-84.
21. Sprengers RW, Teraa M, Moll FL, et al. Quality of life in patients with no-option critical limb ischemia underlines the need for new effective treatment. J Vasc Surg 2010; 52: 843-849, 9 e1.

22. Ozturk C, te Slaa A, Dolmans DE, et al. Quality of life in perspective to treatment of postoperative edema after peripheral bypass surgery. Ann Vasc Surg 2012; 26: 373-382.

23. Dippel E, Shammas N, Takes V, et al. Twelve-month results of percutaneous endovascular reconstruction for chronically occluded superficial femoral arteries: a quality-of-life assessment. $J$ Invasive Cardiol 2006; 18: 316-321.

24. Brothers TE, Robison JG and Elliott BM. Prospective decision analysis for peripheral vascular disease predicts future quality of life. J Vasc Surg 2007; 46: 701-708; discussion 8.

25. Kalbaugh CA, Taylor SM, Blackhurst DW, et al. One-year prospective quality-of-life outcomes in patients treated with angioplasty for symptomatic peripheral arterial disease. J Vasc Surg 2006; 44: 296-302; discussion 3 .

26. Long J, Modrall JG, Parker BJ, et al. Correlation between ankle-brachial index, symptoms, and healthrelated quality of life in patients with peripheral vascular disease. J Vasc Surg 2004; 39: 723-727.

27. Paaske WP and Laustsen J. Femorodistal bypass grafting: quality of life and socioeconomic aspects. Eur J Vasc Endovasc Surg 1995; 10: 226-230.

28. Remes L, Isoaho R, Vahlberg T, et al. Quality of life among lower extremity peripheral arterial disease patients who have undergone endovascular or surgical revascularization: a case-control study. Eur J Vasc Endovasc Surg 2010; 40: 618-625.

29. van Hattum ES, Tangelder MJ, Lawson JA, et al. The quality of life in patients after peripheral bypass surgery deteriorates at long-term follow-up. J Vasc Surg 2011; 53: 643-650.

30. Wohlgemuth WA, Safonova O, Engelhardt M, et al. Improvement of the quality of life concerning the health of patients with peripheral arterial disease (PAD) after successful bypass surgery. Vasa 2008; 37: 338-344.

31. Egberg L, Mattiasson AC, Ljungstrom KG, et al. Healthrelated quality of life in patients with peripheral arterial disease undergoing percutaneous transluminal angioplasty: a prospective one-year follow-up. J Vasc Nurs 2010; 28: 72-77.

32. Bosch JL, van der Graaf Y and Hunink MG. Healthrelated quality of life after angioplasty and stent placement in patients with iliac artery occlusive disease: results of a randomized controlled clinical trial. The Dutch Iliac Stent Trial Study Group. Circulation 1999; 99: 3155-3160.

33. Remes L, Isoaho R, Vahlberg T, et al. Quality of life three years after major lower extremity amputation due to peripheral arterial disease. Aging Clin Exp Res 2010; 22(5-6): 395-405. 